\title{
Kalp Hızı Değişkenliği ve Serebrovasküler Olaylar
}

\section{Heart Rate Variability and Cerebrovascular Events}

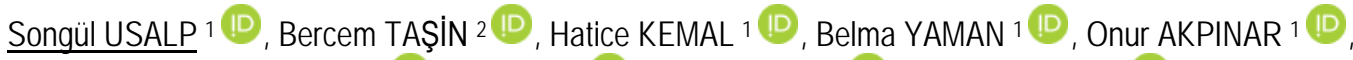 \\ Levent CERIT 1 (D) illker GÜL $1{ }^{\mathbb{D}}$, Aziz GÜNSEL 1 (D) , Hamza DUYGU 1 (D)
}

\author{
1 Yakın Doğu Üniversitesi, Kardiyoloji Ana Bilim Dalı, Lefkoşa, KKTC \\ 2 Batman Bölge Hastanesi , Nöroloji Kliniği, Batman,Türkiye.
}

Öz.

Amaç: Kalp hızı değişkenliği (KHD), kalbin otonomik fonksiyonlarını yansıtan noninvaziv bir değerlendirmedir ve sistemik hastalıklarda bozulduğu bilinmektedir. Çalışmamızda, KHD ile akut iskemik inme (Aii) arasındaki ilişkiyi araştırmayı amaçladık.

Materyal ve metod: Toplam 102 Ail hastası ve 66 sağlıklı birey (kontrol grubu) çalışmaya dahil edildi. Ail hastaları, iskemik inme (ii) ( $n=65)$ ve geçici iskemik atak (GIA) $(n=37)$ olarak iki gruba ayrıldı. Hasta ve kontrol gruplarına 24 saatlik ritim Holter kaydı yapıldı.

Bulgular: Ail grubunda hipertansiyon (\%60.8'e karşın \%33.3, $p=0.005$ ) ve diyabetes mellitus (DM) (\%39.2'e karşın \%15.2, $p=0.002$ ) sıklığı ile, serum glukoz (142.4 \pm 60.0 'a karşı 106.8 $\pm 20.9, p=0.034$ ) ve kreatinin düzeyleri $\left(0.9 \pm 0.3^{\prime}\right.$ e karşın $\left.0.8 \pm 0.5, p=0.010\right)$ anlamlı olarak daha yüksekti, fakat serum yüksek dansiteli lipoprotein düzeyi $(44.7 \pm 9.7$ 'e karşın $54.6 \pm 12.9, p=0.022)$ ve sol ventrikül ejeksiyon fraksiyonu (SVEF) (53.0 [25-60]'a karşın 58.0 [30-60], $p=0.012)$ daha düşüktü. Ek olarak, KHD parametrelerinden olan SDNN (112.2 [37-1473]'e karşın 134.8 [37-405], p<0.001), SDNN index (44.0 [14-132]'e karşın 55.1 [24-145], p<0.001), üçgen index (1.5 [1-36]'e karşın 2.0 [1-53], $p<0.001), \mathrm{HF}$ (22.1 [5-2023]'e karşın 28.0 [13-2701], $p=0.014), \operatorname{LF}$ (2.7 [13-2367]'e karşın 3.4 [4-1523], p<0.001) ve VLF (676.3 [7-1795]'e karşın 1014 [291-1881], p<0.001) Ail grubunda anlamlı olarak daha düşüktü. ii ve GIA grupları arasında ise bazal özellikler ve KHD parametreleri açısından anlamlı bir farklıık izlenmedi ( $p>0.05$, hepsi için). Çoklu regresyon analizlerinde, yaş (OR: 1.096, \%95 GA: $1.056-1.136, p<0.001)$, SVEF (OR: 0.362 , \%95 GA: 0.355-0.559, p=0.006) ve DM (OR: 0.860, \%95 GA: 0.856-0.931, p<0.001) inme için bağımsız bir risk faktörü olarak saptandı

Sonuç: Çalışmamızda Ail hastalarında KHD parametrelerinin azalmış olduğunu saptadık. Ek olarak; yaş, SVEF ve DM'nin Aili için bağımsız birer risk faktörü olduğunu bulduk.

Anahtar Kelimeler: Akut serebrovasküler hastalık, Kalp hızı, İskemik inme, Geçici iskemik atak

\section{Abstract}

Background: Heart rate variability (HRV) is a noninvasive assessment that reflects the autonomic functions of the heart and it is known to be disrupted in many systematic diseases. In our study, we aimed to investigate the relationship between HRV and acute ischemic stroke (AIS).

Materials and Methods: 102 AIS patients and 66 healthy individuals (control group) were included in the study. AIS patients were divided into two groups as ischemic stroke (IS) $(n=65)$ and transient ischemic attack (TIA) (n=37). A 24-hour rhythm Holter record were applied to all patients.

Results: The frequency of hypertension $(60.8 \%$ vs. $33.3 \%, p=0.005)$ and diabetes mellitus (DM) $(39.2 \%$ vs. $15.2 \%, p=0.002)$, and serum glucose $(142.4 \pm 60.0$ vs. $106.8 \pm 20.9, p=0.034)$ and creatinine levels $(0.9 \pm 0.3$ vs. $0.8 \pm 0.5, p=0.010)$ were significantly higher in AIS group, whereas serum high-density lipoprotein $(44.7 \pm 9.7 \mathrm{vs}$. $54.6 \pm 12.9, p=0.022)$ and left ventricular ejection fraction (LVEF) values were lower (53.0 [25-60] vs. 58.0 [30$60], p=0.012$ ). Also, the HRV parameters SDNN (112.2 [37-1473] vs. 134.8[37-405], $p<0.001)$, SDNN index (44.0 [14-132] vs. 55.1 [24-145], $p<0.001)$, triangular index (1.5 [1-36] vs. 2.0 [1-53], $p<0.001), \mathrm{HF}(22.1$ [5-2023] vs. 28.0 [13-2701], p=0.014), LF 2.7 [13-2367] vs. 3.4 [4-1523], $p<0.001)$, and VLF 676.3 [7-1795] vs. 1014 [2911881], $p<0.001$ ) were lower in the AIS group. There was no significant difference between the TIA and IS groups in terms of basal characteristics and HRV ( $p>0.05$, for all). In multivariable regression analysis, age (OR: 1.096, \%95 Cl: $1.056-1.136, p<0.001$ ), LVEF (OR: 0.362, \% 95Cl: 0.355-0.559, $p=0.006$ ) and DM (OR: $0.860, \%$ 95Cl: 0.856-0.931, p<0.001) were independent risk factors for AIS.

Conclusion: In our study, we detected that HRV parameters were lower in patients with AIS. We also found that age, LVEF and DM were the independent risk factors for AIS.

Key words: Acute cerebrovascular disease, Heart rate, Ischemic stroke, Transient ischemic attack

\section{Sorumlu Yazar I \\ Corresponding Author}

\section{Dr. Songül USALP}

Near East Hospital University Hospital, Near East Boulevard 99138, Nicosia, CYPRUS

Tel: +90392675 1000

Faks: +90 (392) 2236461

e-mail: dr.songulusalp@hotmail.com

Geliş tarihi / Received: 14.06.2020

Kabul tarihi / Accepted: 10.11.2020

DOI: 10.35440/hutfd.752701 


\section{Giriş}

Serebrovasküler hastalıklar (SVH), iskemik kalp hastalıklarından sonra dünya genelindeki ikinci en önemli ölüm nedeni olmaya devam etmektedir (1). SVH, beynin bir bölgesinin geçici veya kalıcı olarak, iskemi veya kanama nedeniyle etkilendiği, beyin damarlarını da ilgilendiren tüm hastalıkları kapsar. Akut iskemik inme (Aii), tüm SVH'ların yaklaşık \%80'ini oluşturmaktadır (2). Aill'in ciddi bir formu olan iskemik inmede (ii), serebral arterde meydana gelen trombotik tıkanma sonrası, istenmeyen nörolojik olaylar gelişebilir. Ail'nin hafif bir formu olan geçici iskemik atak (GiA) ise, akut enfarktüs olmadan, geçici nörolojik disfonksiyon atağı olarak yorumlanır. Yaklaşık 24 saat süren fokal serebral fonksiyon kaybıdır ve semptomlar kısa olup çoğunlukla kendiliğinden düzelir $(1,2)$.

İskemik inme hastaları, hastalığın ciddiyetine göre yoğun bakım intiyacı gerektirebilirler ve mortalite bu hastalarda daha yüksektir. Hastaneden taburcu olsalar dahi, bu hastalar çoğu zaman başkasının yardımına muhtaç olabilirler. Bu nedenle, inme gelişme intimali olan hastaları saptamak önemlidir. İnme için en önemli risk faktörlerinin başında ileri yaş gelmektedir. Koroner arter hastalığında olduğu gibi, Ail'de de cinsiyet, ırk, aile öyküsü başıca değiştirilemeyen risk faktörlerindendir $(3,4)$. Ayrıca hipertansiyon, diyabetes mellitus, hiperlipidemi, sigara, alkol kullanımı, geçirilmiş kardiyovasküler hastalıklar, atriyal fibrilasyon, obezite ve kan pıhtılaşmasına eğilim yaratan hastalıklar da Aili riskini artıran durumlardandır (3-5). Bu hastalıkların çoğunda, esas patolojiye ek olarak otonomik disfonksiyon da tabloya eşlik edebilmektedir (6-8). Otonomik disfonksiyonun tanısında çeşitli yöntemler kullanılmaktadır $(9,10)$. Bunlardan biri olan kalp hızı değişkenliği (KHD), kalbin otonomik fonksiyonları hakkında bilgi edinmemizi sağlar (10). Stres karşısında artan sempatik sistemin baskın hale gelmesi kalp hızının artmasına, dinlenme fazında ise parasempatik sistemin baskınlaşması kalp hızının yavaşlamasına neden olur ve normal kişilerde birbiriyle uyum içinde çalışan bu denge bazı hastalıkların sürecinde bozulabilmektedir. Otonomik dengenin bozulması, KHD'in azalmasına ve istenmeyen kardiyovasküler olaylara neden olabilmektedir $(11,12)$. Literatürde Aili ile başvuran hastalarda KHD'yi inceleyen çalışmalar sınırıdır. Bu çalışmamızdaki amacımız, Ail tanısı konulan hastalarda KHD'nin klinik önemini araştırmaktır.

\section{Materyal ve Metod \\ Çalışma popülasyonu}

Çalışmamıza, kliniğimize Ail tanısıyla başvuran toplam 102 hasta ve 66 sağlıklı birey (kontrol grubu) dahil edildi. Kafa içi kanama, ciddi karotis darlığı, supraventriküler ya da ventriküler aritmi, kalp pili, ciddi kalp kapak hastalığı, kronik böbrek yetersizliği, karaciğer hastalığı olanlar ve çaIışmaya katılımak için rıza göstermeyenler çalışmaya dahil edilmedi. Bununla beraber, atrial fibrilasyon ritminde olan ya da altı saniye üzerinde paroksismal atriyal fibrilasyon atakları olan, 24 saatlik ritim holter kaydında aşırı artefakt bulunanlar, 22 saatin altında holter kaydı olan ve sık VES (24 saat boyunca \%10'un üzerinde) atakları olan toplam dokuz hasta da çalışmaya alınmadı. Çalışma yerel etik kurul tarafından onaylandı (YDU/2019/66-729) ve Helsinki Bildirgesi'nin kurallarına uygun olarak uygulandı. Tüm hastalardan yazılı bilgilendirilmiş onam alındı.

Tüm hastaların bazal demografik özellikleri kaydedildi. Hastalar nöroloji uzmanı tarafından değerlendirildi ve Ail tanısı Amerikan İnme Derneği önerileri baz alınarak konuldu (2). Nörolojik değerlendirme yapııırken hastalar, National Institude Health Stroke Skalasına (NIHSS) göre değerlendirildi (2). Ail tanısı ve beyin hasarının etyolojisini araştırmak (iskemi veya kanama) amacıyla beyin tomografisi ve beyin manyetik rezonans görüntüleme incelemeleri yapıldı. Tüm hastalardan en az 8 saat açlık sonrası venöz kan örnekleri alındı ve standart laboratuvar yöntemleri kullanılarak biyokimyasal ve hematolojik analizler yapıldı.

\section{Elektrokardiyografik ve ekokardiyografik analiz}

Tüm hastalara sırtüstü yatar pozisyonda $25 \mathrm{~mm} / \mathrm{ms}$ ve 10 $\mathrm{mV} / \mathrm{sn}$ hızında 12 derivasyonlu yüzey elektrokardiyografi (EKG) kaydı alındı (GE Marquette Mac 1200, GE Healthcare 3000 North Grandview Waukesha, WI 53188 U.S.A.). Ekokardiyografik incelemeler sol yan yatar pozisyonunda Vivid 7 Pro ultrason görüntüleme sistemi (GE Vingmed, Milwaukee, Wisconsin, USA) kullanılarak yapıldı. Konvansiyonel Doppler ekokardiyografi incelemeleri ve M-mod ölçümleri Amerikan Ekokardiyografi Derneği tarafından yayınlanan standartlara göre yapıldı (13). Sol ventrikül ejeksiyon fraksiyonu (SVEF) Simpson'ın kuralına göre hesaplandı (13).

Ritim holter analizi ve Kalp Hızı Değişkenliği Öıçümleri: Tüm hastalara, başvurularının ardından ilk 72 saat içinde 24 saatlik ritim Holter kaydı yapıldı. Holter kayıtları Cardioscan 12.0 (DM Software Inc., Stateline, NV, US) yazılımı ile analiz edildi. Tüm kayıtlar, Avrupa Kardiyoloji Cemiyeti ve Kuzey Amerika Pil ve Elektrofizyoloji Cemiyeti görüşlerine uygun olarak yapıldı ve bu kayıt sonuçları daha sonra iki farklı kardiyolog tarafından yorumlandı $(14,15)$. KHD ölçümü yapıııken, belirgin olan $\mathrm{R}$ dalgaları referans alındı. Holter kaydındaki veri işleme programında oluşturulan görüntü dosyasındaki normal-normal (NN) R aralıkları yapılandııılarak, bilgisayarlı KHD ölçümleri baz alındı $(14,15)$. KHD ölçümü için kullanılan parametreler üç ana başlık altında toplanabilir: Zaman temelli ölçümler, spektral ya da frekans temelli ölçümler ve doğrusal olmayan geometrik ölçümler. Zaman temelli ölçümlerde, iki komşu $R$ dalgası arasındaki interval (NN intervali) holter kaydı boyunca ölçülür. SDNN, zaman bazlı ölçümlerin en sık kullanılanıdır ve 24 saatlik kayıt boyunca bütün RR (NN) intervallerinin standart deviasyonu olarak adlandırılır (15). SDNN indexi, 24 saat içinde tüm 5 dakikalık segmentler için tüm NN ara- 
lıklarının standart sapmalarının ortalamasıdır. rMSSD, ardışık NN aralığı farklıııklarının karelerinin ortalamasının köküdür. pNN50, bir önceki aralıktan $>50 \mathrm{~ms}$ farklı NN aralıklarının yüzdesidir. Üçgen indeks, NN aralıklarının toplam sayısının NN histogram yüksekliğine bölünmesiyle elde edilir (16).

Spektral veya frekans temelli yapılan ölçümler, 0 ila $0.5 \mathrm{~Hz}$ arasında değişen 5 frekans bandından oluşan güç spektral yoğunluk analizi kullanılarak hesaplanır. Düşük frekanslı (LF), orta frekanslı (MF) ve yüksek frekanslı (HF) bantlar toplam gücün sadece $\% 5$ 'ini oluşturur. HF, izole parasempatik aktivitenin bir ölçüsü olarak kabul edilir. LF ise parasempatik sistemin etkisi ile modüle edilen ağırlıkı olarak sempatik aktivitenin bir ölçüsü olarak kabul edilir. Toplam gücün çoğunu oluşturan ultra düşük frekanslı (ULF) ve çok düşük frekanslı (VLF) bantlar, HF ve LF gücünden çok daha az netliktedirler $(17,18)$.

\section{İstatistiksel analizler}

Elde edilen veriler SPSS 20.0 versiyonu (Statistical Package for Social Sciences, Inc., Chicago, IL, USA) istatistik programına kaydedildi. Verilerin normal dağılıma uygun olup olmadığı Kolmogorov Smirnov testi ile değerlendirildi. Normal dağılım gösteren sayısal değişkenler ortalama \pm standart sapma olarak, kategorik değişkenler yüzde (\%) olarak ifade edildi. Normal dağııım gösteren veriler iki grup arasında karşılaştırılırken Students t-test, kategorik değişkenlerin karşılaştıııırken Ki-Kare testi kullanıldı. Normal dağılım göstermeyen veriler ise median [minimum-maximum] değerleri ile ifade edildi ve Mann-Whitney $U$ testi ile karşılaştııldı. İnmenin, bağımsız öngördürücülerini belirlemek için çok değişkenli lojistik regresyon analizi kullanıldı. Tüm sonuçlarda $p<0.05$ değeri anlamlı kabul edildi.

\section{Bulgular}

Çalışmaya, hastanemiz nöroloji kliniğinde değerlendirilerek Ail tanısı almış toplam 102 hasta (ortalama yaş $69.7 \pm$ 9.6 yıl, \% 43.6 erkek) ve 66 kontrol grubu (ortalama yaş $62.9 \pm 12.4$ yıl, $\% 53.9$ erkek) alındı.

Ail hastaları ile kontrol grubunun demografik ve klinik özellikleri ile 24 saatlik ritim holter verilerinden elde edilen değerler Tablo 1'de gösterilmiştir. Kontrol grubu ile Ail hastaları arasında, yaş $(p=0.057)$ ve cinsiyet $(p=0.206)$ açısından anlamlı bir fark saptanmadı. Ancak, Ail grubunda hipertansiyon (HT) (\%60.8'e karşın \%33.3, $p=0.005)$ ve diyabetes mellitus (DM) (\%39.2'e karşın \%15.2, $p=0.002$ ) sıklı̆ı ile, serum glukoz (142.4 \pm 60.0 'a karşı $106.8 \pm 20.9$, $\mathrm{p}=0.034)$ ve kreatinin düzeyleri $(0.9 \pm 0.3$ 'e karşın $0.8 \pm 0.5$, $\mathrm{p}=0.010$ ) anlamlı olarak daha yüksekken, yüksek dansiteli lipoprotein düzeyi $(44.7 \pm 9.7$ 'e karşın $54.6 \pm 12.9, p=0.022)$ ve sol ventrikül ejeksiyon fraksiyonu (SVEF) (53.0 [2560]'a karşın 58.0 [30-60], p=0.012) daha düşüktü. KHD parametreleri değerlendirildiğinde, Ail grubunda SDNN (112.2 [37-1473]'e karşın 134.8 [37-405], $p<0.001$ ), SDNN index (44.0 [14-132]'e karşın 55.1 [24-145], $\mathrm{p}=0.001)$, üçgen index (1.5 [1-36]'e karşın 2.0 [1-53], $\mathrm{p}<$ 0.001), HF (22.1 [5-2023]'e karşın 28.0 [13-2701], $p=0.014)$, LF (2.7 [13-2367]'e karşın 3.4 [4-1523], $p<$ $0.001)$ ve VLF'nin (676.3 [7-1795]'e karşın 1014 [2911881], $p$ < 0.001) anlamlı olarak daha düşük olduğu tespit edildi (Tablo 1).

Tablo 1. Akut iskemik inme (Aii) hastaları ile kontrol grubunun demografik, klinik özelliklerinin ve KHD parametrelerinin karşılaştırıması

\begin{tabular}{|c|c|c|c|}
\hline Değişkenler & $\begin{array}{l}\text { Kontrol grubu } \\
(n=66)\end{array}$ & $\begin{array}{l}\text { Ail grubu } \\
(n=102)\end{array}$ & $\begin{array}{l}\text { p- } \\
\text { değeri }\end{array}$ \\
\hline Yaş (yıl) & $62.9 \pm 12.4$ & $69.7 \pm 9.6$ & 0.057 \\
\hline Erkek cinsiyet (\%) & $29(43.9)$ & $55(53.9)$ & 0.206 \\
\hline HT (\%) & $22(33.3)$ & $62(60.8)$ & 0.005 \\
\hline DM (\%) & $10(15.2)$ & 40 (39.2) & 0.002 \\
\hline Serum glukoz (mg/dl) & $106.8 \pm 20.9$ & $142.6 \pm 60.0$ & 0.034 \\
\hline $\begin{array}{l}\text { Serum } \\
\text { kreatinin (mg/dl) }\end{array}$ & $0.8 \pm 0.5$ & $0.9 \pm 0.3$ & 0.010 \\
\hline $\mathrm{Hgb}(\mathrm{gr} / \mathrm{dl})$ & $13.7 \pm 1.4$ & $13.4 \pm 1.5$ & 0.107 \\
\hline LDL kolesterol (mg/dL) & $115.8 \pm 35.9$ & $119.9 \pm 39.7$ & 0.547 \\
\hline HDL kolesterol (mg/dL) & $54.6 \pm 12.9$ & $44.7 \pm 9.7$ & 0.022 \\
\hline $\mathrm{EF}(\%)$ & $58.0(30-60)$ & $53.0(25-60)$ & $0.012^{*}$ \\
\hline Ortalama KH (atım/dk) & $71.4 \pm 8.1$ & $80.0 \pm 62.7$ & 0.272 \\
\hline SDNN (ms) & $134.8(37-405)$ & $\begin{array}{l}112.2 \\
(37-1473)\end{array}$ & $0.001^{*}$ \\
\hline SDNN index (ms) & $55.1(24-145)$ & $44.0(14-132)$ & $0.001^{*}$ \\
\hline rMSSD (ms) & $29.9(8-84)$ & $29.5(1-105)$ & $0.324^{*}$ \\
\hline pNN50 (\%) & $9.5(0-145)$ & $8.2(0-51)$ & $0.222^{\star}$ \\
\hline Üçgen index (ms) & $2.0(1-53)$ & $1.5(1-36)$ & $0.001^{*}$ \\
\hline $\mathrm{HF}\left(\mathrm{ms}^{2}\right)$ & $28.0(13-2701)$ & $22.1(5-2023)$ & $0.014^{*}$ \\
\hline $\mathrm{LF}\left(\mathrm{ms}^{2}\right)$ & $3.4(4-1523)$ & $2.7(13-2367)$ & $0.001^{*}$ \\
\hline $\operatorname{VLF}\left(\mathrm{ms}^{2}\right)$ & 1014 (291- 1881) & $676.3(7-1795)$ & $0.001^{*}$ \\
\hline
\end{tabular}

* Mann-Whitney U test, ortanca, max ve min değerler yazılmıştır.

DM: Diabetes mellitus; EF: Ejeksiyon Fraksiyonu; HDL: Yüksek yoğunluklu lipoprotein; Hgb: Hemoglobin; HF: Yüksek frekans bandl; HT: Hipertansiyon; KH: Kalp hızı; LDL: Düşük yoğunluklu lipoprotein; LF: Düşük frekans bandı, pNN50: Elli milisaniyeyi aşan ardışık NN intervalleri arasındaki farkın yüzdesi; rMSSD:Ardışık normal NN intervalleri arasındaki farkların karekökü; SDNN: NN intervallerinin standart sapmasi; SDNN index:24 saat içinde tüm 5 dakikalık segmentler için tüm NN aralıklarının standart sapmalarının ortalaması; SPAB:Sistolik pulmoner arter basıncı; VLF:Çok düşük frekans bandı.

Ail alt tiplerinde KHD parametrelerini değerlendirmek için hasta grubumuz GIA ve Ii şeklinde 2 gruba ayrıldı. GIA ve 
ii gruplarının demografik ve klinik özellikleri ile 24 saatlik ritim holter verilerinden elde edilen değerler Tablo 2'de gösterilmiştir. Her 2 grup arasında bu özellikler açısından anlamlı bir fark olmadığı görüldü (Tablo 2).

Tablo 2. İskemik inme (ii) ve geçici iskemik atak (GIA) olan hastaların, demografik, klinik özelliklerinin, KHD parametrelerinin karşılaştırılması

\begin{tabular}{|c|c|c|c|}
\hline Değişkenler & $\begin{array}{l}\text { GíA grubu } \\
(n=37)\end{array}$ & $\begin{array}{l}\text { îl grubu } \\
(n=65)\end{array}$ & $\begin{array}{l}\text { p- } \\
\text { değeri }\end{array}$ \\
\hline Yaş (yıl) & $67.5 \pm 10.5$ & $71.0 \pm 8.6$ & 0.072 \\
\hline Erkek cinsiyet (\%) & $20(54.1)$ & $35(53.8)$ & 0.092 \\
\hline HT (\%) & $19(63.2)$ & $46(70.8)$ & 0.061 \\
\hline $\mathrm{DM}(\%)$ & $13(35.1)$ & $27(41.5)$ & 0.744 \\
\hline $\begin{array}{l}\text { Serum } \\
\text { glukoz (mg/dl) }\end{array}$ & $138.4 \pm 51.5$ & $145.0 \pm 64.6$ & 0.598 \\
\hline $\begin{array}{l}\text { Serum } \\
\text { kreatinin (mg/dl) }\end{array}$ & $0.8 \pm 0.2$ & $0.9 \pm 0.3$ & 0.059 \\
\hline $\mathrm{Hgb}(\mathrm{gr} / \mathrm{dl})$ & $13.7 \pm 1.4$ & $13.4 \pm 1.5$ & 0.107 \\
\hline $\begin{array}{l}\text { LDL } \\
\text { kolesterol (mg/dL) }\end{array}$ & $110.3 \pm 40.8$ & $126.2 \pm 38.1$ & 0.070 \\
\hline $\begin{array}{l}\mathrm{HDL} \\
\text { kolesterol (mg/dL) }\end{array}$ & $45.5 \pm 10.2$ & $44.3 \pm 9.4$ & 0.597 \\
\hline $\mathrm{EF}(\%)$ & $55.0(34-60)$ & $52.0(25-60)$ & $0.092^{*}$ \\
\hline $\begin{array}{l}\text { Ortalama } \\
\text { KH (atım/dk) }\end{array}$ & $70.8 \pm 14.1$ & $85.2 \pm 77.6$ & 0.270 \\
\hline SDNN (ms) & $144.5(52-1473)$ & $93.8(37-180)$ & $0.076^{*}$ \\
\hline SDNN index (ms) & $46.8(19-132)$ & $42.4(14-102)$ & $0.378^{\star}$ \\
\hline rMSSD (ms) & $31.1(9-105)$ & $28.6(1-102)$ & $0.648^{*}$ \\
\hline pNN50 (\%) & $7.8(0-40)$ & $8.5(0-51)$ & $0.617^{*}$ \\
\hline Üçen index (ms) & $1.7(1-18)$ & $1.3(1-20)$ & $0.121^{*}$ \\
\hline $\mathrm{HF}\left(\mathrm{ms}^{2}\right)$ & $241.9(13-1723)$ & $207.6(5-2023)$ & $0287^{*}$ \\
\hline $\mathrm{LF}\left(\mathrm{ms}^{2}\right)$ & $376.5(30-2089)$ & $269.3(13-2367)$ & $0.115^{\star}$ \\
\hline $\operatorname{VLF}\left(\mathrm{ms}^{2}\right)$ & $729.3(91-1784)$ & $646.1(7-1795)$ & $0.273^{*}$ \\
\hline \multicolumn{4}{|c|}{$\begin{array}{l}\text { *: Mann-Whitney U test, ortanca, max ve min değerler yazılmıştır. } \\
\text { DM: Diyabetes mellitus; EF: Ejeksiyon Fraksiyonu; HDL: Yüksek yoğunluklu li- } \\
\text { poprotein; Hgb: Hemoglobin; HF: Yüksek frekans bandı; HT: Hipertansiyon; KH: } \\
\text { Kalp hızl; LDL: Düşük yoğunluklu lipoprotein; LF: Düsük frekans bandı, pNN50: } \\
\text { Elli milisaniyeyi aşan ardışı NN intervalleri arasındaki farkın yüzdesi; rMSSD:Ar- } \\
\text { dışık normal NN intervalleri arasındaki farkların karekökü; SDNN: NN intervalle- } \\
\text { rinin standart sapması; SDNN index:24 saat içinde tüm } 5 \text { dakikalık segmentler } \\
\text { çin tüm NN aralıklarııın standart sapmalarının ortalamasl; sPAP:sistolik pulmo- } \\
\text { ner arter basıncl; VLF:Çok düşük frekans bandı. }\end{array}$} \\
\hline
\end{tabular}

Tablo 3. İnme ile ilişkili olabilecek bağımsız risk faktörlerinin çok değişkenli lojistik regresyon analizi ile değerlendirilmesi

\begin{tabular}{|l|l|l|l|}
\hline Değişkenler & OR & 95 \% GA & $\mathbf{p}$ \\
\hline Yaş (yll) & 1.096 & $(1.056-1.136)$ & $<0.001$ \\
\hline EF (\%) & 0.362 & $(0.355-0.559)$ & 0.006 \\
\hline Hipertansiyon & 0.586 & $(0.270-1.273)$ & 0.177 \\
\hline Diyabetes mellitus & 0.860 & $(0.856-0.931)$ & $<0.001$ \\
\hline SDNN (ms) & 0.997 & $(0.991-1.002)$ & 0.257 \\
\hline SDNN index (ms) & 0.987 & $(0.954-1.022)$ & 0.463 \\
\hline Üçgen (ms) & 1.062 & $(0.896-1.017)$ & 0.373 \\
\hline HF $\left(\mathrm{ms}^{2}\right)$ & 0.998 & $(0.994-1.001)$ & 0.192 \\
\hline LF $\left(\mathrm{ms}^{2}\right)$ & 1.001 & $(0.999-1.003)$ & 0.443 \\
\hline VLF $\left(\mathrm{ms}^{2}\right)$ & 0.999 & $(0.998-1.001)$ & 0.222 \\
\hline
\end{tabular}

GA: Güven Aralığı; EF: Ejeksiyon Fraksiyonu; HF: Yüksek frekans bandl; LF: Düşük frekans bandı; OR: Odds ratio; SDNN: NN intervallerinin standart sapması; SDNN index:24 saat içinde tüm 5 dakikalık segmentler için tüm NN aralıklarının standart sapmalarının ortalaması; VLF: Çok düşük frekans bandı.

Ail'nin bağımsız öngördürücülerini tespit etrmek amacıyla çok değişkenli lojistik regresyon analizi yapıldı. Buna göre; yaş (odds ratio [OR]: 1.096, \%95 güven aralığı [GA]: 1.056 - 1.136, $p<0.001$ ), SVEF değeri (OR: 0.362, \%95 GA: $0.355-0.559, p=0.006$ ) ve DM (OR: $0.860, \%$ 95GA: 0.856$0.931, p<0.001)$ inme için bağımsız risk faktörleri olarak saptandı (Tablo 3).

\section{Tartışma}

Bu çalışmada, Ail tanısı konulan hastalarda KHD'nin klinik önemi araştırdık. Çalışmamızın ana bulgusu, Ail ile başvuran hastalarda KHD'nin anlamlı bir şekilde azaldığıdır. Ek olarak, yaş, DM ve SVEF'nin de Ail için bağımsız birer risk faktörü olduğunu tespit ettik.

Kalp hızı hem sempatik hem de parasempatik sistemin etkilerine yanıt olarak atımdan atıma değişkenlik gösterir. Bu değişkenlik, bazı hastalıkların seyrinde gelişen otonomik disfonksiyona bağlı olarak bozulabilir. Kardiyak otonomik fonksiyonların değerlendirilmesinde birçok yöntem kullanılmış olsa da daha güvenilir bilgi verdiği için 24 saatlik ritm Holter klinik pratikte sıklıkla kullanılmaktadır $(10,16)$. Çalışmamızda da Ail hastalarına 24 saatlik ritim holter kaydı uygulanarak otonomik disfonksiyon araştırıldı ve KHD parametrelerinin Ail hastalarında anlamlı olarak düşük olduğu görüldü. Çalışmamıza benzer şekilde Korpelainen ve ark.'ları da Ail hastalarında KHD parametrelerini düşük olarak saptamışlardır (19). Bir başka çalışmada ise, sürekli EKG kayıtları kullanılarak KHD parametrelerinin tüm nedenlere bağlı mortalite ile ilişkisi incelenmiş ve VLF, LF, $\mathrm{HF}, \mathrm{TP}$ ve SDNN değerlerinin tüm nedenli mortalite ile ilişkili olduğu bulunmuştur (20). Yine bu sonuçlara paralel olarak, Binici ve ark.'ları sağlıklı orta yaş grubunda KHD parametrelerinin düşüklüğünün inme için öngördürücü olduğunu ve özellikle gece zamanı ölçülen SDNN parametrelerinin inme ile ciddi ilişkili olduğunu saptamışlardır (21). Tüm bu bulgular beraber değerlendirildiğinde, Ail hastalarında otonomik disfonksiyona bağlı olarak KHD parametrelerinin azaldığı ve KHD azalmış Ail hastalarında prognozun daha kötü olduğu söylenebilir.

Frekans bazlı ölçümlerinin 24 saatlik ritim holteri ile değerlendirildiği bir çalışmada, VLF'nin tüm nedenlere bağlı mortaliteyi öngörmede LH ve HF'ye göre daha üstün olduğu bulunmuştur (22). Normalde, LF ve HF değerleri 24 saatlik kayıtlarda sirkadien ritm göstermektedir. LF gün boyunca yüksek iken, HF ise geceleri daha baskındır (22). Bu nedenle, LF/HF oranı artmış vagal aktivasyonun bir kriteri olarak düşünülmektedir (22). Çalışmamızda da Ail olan hastalarda, frekans bazlı ölçümler değerlendirilmiş ve bu değerlerin Aili grubunda daha düşük olduğu bulunmuştu. Ancak, Aili için yapılan lojistik regresyon analizinde bu parametrelerin Aili için bağımsız bir risk faktörü olmadıkları tespit edilmişti. Bunun nedeni, çalışmamızdaki hasta sayısının az olması ile açıklanabilir. Ek olarak, hastalarımızın uzun dönem kayıtları mevcut olmadığı için bu parametrelerin mortalite ile ilişkisini de değerlendiremedik.

Ail için birçok geleneksel ve değiştirilemeyen risk faktörleri 
mevcuttur. Çalışmamızda, Ail hastalarında, HT ve DM sıklığının kontrol grubuna göre daha fazla olduğu tespit edildi. Aslında, bu hastaların çoğu hastalıklarının farkında değillerdi ve yatışları esnasında HT ve DM tanısı almışlardı. Ayrıca, inme sonrası sempatik sistemin aktive olması, kan şekerinin ve kan basıncı oranının yükselmesine ve dolayısıyla da hastalarımızın daha fazla diyabet ve hipertansiyon tanısı almasına neden olabileceği de söylenebilir. Ail hastalarında ek olarak, serum kreatinin seviyelerinin daha yüksek, yüksek dansiteli lipoprotein ve SVEF değerlerinin ise daha düşük olduğunu tespit ettik. Ancak, çok değişkenli lojistik regresyon analizi yaptığımızda, tüm bu risk faktörleri içerisinde, sadece yaş, DM ve SVEF'nin bağımsız birer risk faktörü olduğunu tespit ettik. Elde ettiğimiz bulgularımı, mevcut literatür bilgileri ile örtüşmektedir $(3,4)$.

Çalışmamızın en büyük kısıtıılı̆ı hasta sayısının yetersiz olmasıdır. Ek olarak, hastalar kötü olaylar açısından takip edilmemişlerdi. KHD'nin hastane içi ve uzun dönem kötü sonuçlar ile ilişkisinin belirlenmesi çalışmamıza ek katkı sağlayabilirdi. Bu konuda, daha fazla hasta sayısı ile yapılan ve uzun dönem hasta takiplerinin yapılacağı ileriye dönük çalışmalara intiyaç olduğunu düşünmekteyiz.

Sonuç olarak, bu çalışmada Ail hastalarında KHD parametrelerinin klinik önemini değerlendirdik ve KHD parametrelerinin Ail'de azaldığını tespit ettik. Ail alt gruplarında ise KHD parametreleri açısından anlamlı bir fark olmadığını saptadık.

Etik Kurul Onayı: Yakın Doğu Üniversitesi Bilimsel araştırmalar değerlendirme etik kurulundan, Etik onam alınmıştır. (Tarih: 28/02/2019 No: YDU/2019/66-729).

Çıkar çatışması : Yazarlar arasında herhangibir çıkar çatışması saptanmamıştır.

Finansal Destek: Yazarlar, bu çalışmada herhangbir finansal destek almadıklarını beyan etmişlerdir.

\section{Kaynaklar}

1. Sacco RL, Kasner SE, Broderick JP, Caplan LR, Connors JJ, Culebras $A$, et al. An updated definition of stroke for the 21st century: a statement for healthcare professionals from the American Heart Association/American Stroke Association. Stroke 2013; 44(7):2064-89.

2. Powers WJ, Rabinstein AA, Teri Ackerson, Adeoye OM, Bambakidis NC, Becker K, et al. Guidelines fort he Early Management of Patients With Acute Ischemic Stroke: 2019 Update to the 2018 Guidelines fort he Early Management of Acute Ischemic Stroke: A Guideline for Healthcare Professionals From the American Heart Association/ American Stroke Association. Stroke. 2019;50(12):344-418.

3. Utku U. İnme Tanımı, Etyolojisi, Sınıflandırma ve Risk Faktörü. Türkiye Fiziksel Tıp Dergisi Özel Sayı: 2007; 53:1-3

4. Boehme AK, Esenwa C, Elkind MSV. Stroke Risk Faktors, Genetics, and Prevention.Circ Res. 2017 ;120:472- 495

5. Kayran Y, Yayla V, Çabalar M, Bajrami A, Karamanli Y, Gedikbaşi A, et al. LDL Subclasses in Ischemic Stroke: A Risk Factor? Noro Psikiyatr Ars. $2019 ; 56(1): 13-17$.

6. Lip GY, Nieuwlaat R, Pisters R, Lane DA, Crijns HJ. Refining clinical risk stratification for predicting stroke and thrombi-embolism in atrial fibrillation using a novel risk factor-based approach: the Euro Heart Survey on atrial fibrillation. Chest 2010;137:263-272.
7. Guidelines for the management of atrial fibrillation The Task Force for the Management of Atrial Fibrillation of the European Society of Cardiology (ESC) Developed with the special contribution of the Europan Heart Rhythm Association (EHRA) Endorsed by the European Association for Cardio-Thoracic Surgery (EACTS). Eur Heart J 2010;31:2369-2429. 8. Saladini F, Di Marco A, Palatini P. Autonomic Dysfunction: How to Identify and When to Treat? High Blood Press Cardiovasc Prev. 2016;23(3):237-43.

9. Al-Qudah ZA, Yacoub HA, Souyah N. Disorders of the Autonomic Nervous System after Hemispheric Cerebrovascular Disorders: An Update. J Vasc Interv Neurol. 2015;8(4):43-52.

10. Gernot Ernst.Heart-Rate Variability-More than Heart Beats? Front Public Health. 2017:5:240.

11. Kleiger RE, Miller JP, Bigger JT Jr, Moss AJ. Decreased heart rate variability and its association with increased mortality after acute myocardial infarction. Am J Cardiol. 1987;59(4):256-62.

12. Bodapati RK, Kizer JR, Kop WJ, Kamel H, Stein PK. Addition of 24Hour Heart Rate Variability Parameters to the Cardiovascular Health Study Stroke Risk Score and Prediction of Incident Stroke: The Cardiovascular Health Study. J Am Heart Assoc. 2017;6: (7). pii: e004305.

13. Mitchell C, Rahko PS, Blauwet LA, Canaday B, Finstuen JA, Foster MC, et al.Guidelines for Performing a Comprehensive Transthoracic Echocardiographic Examination in adults: Recommendation from the American Society of Echocardiography.J Am Soc Echocardiogr. 2019;32(1):1-64.

14. Taylor JA, Lipsitz LA. Heart rate variability standards. Circulation 1997;(95)1280-281.

15. Pieper SJ, Hammill SC. Heart rate variability : Technique and investigational applications in cardiovascular medicine. Mayo Clin Proc 1995;70(10): 955-964.

16. Sztajzel J. Heart rate variability: a noninvasive electrocardiographic method to measure the autonomic nervous system.Swiss Med Wkly. 2004:134(35-36):514-22.

17. Novak V, Saul JP, Eckberg DL. Task Force report on heart rate variability. Circulation.1997;96(3): 1056-1057.

18. Shaffer F, Ginsberg JP. An overview of Heart Rate Variability Metrics and Norms. Front Public Health. 2017;5:258.

19. Korpelainen JT, Sotaniemi KA, Mäkikallio A, Huikuri HV, Myllylä VV. Dynamic behavior of heart rate in ischemic stroke. Stroke. 1999;30(5):1008-13.

20. Tsuji H, Venditti FJ Jr, Manders ES, Evans JC, Larson MG, Feldman $\mathrm{CL}$, et al. Reduced heart rate variability and mortality risk in an elderly cohort. The Framingham Heart Study. Circulation 1994;90(2): 878-93.

21. Binici Z, Mouridsen MR, Køber L, Sajadieh A. Decreased nighttime heart rate variability is associated with increased stroke risk. Stroke. 2011;42:3196-201.

22. Kleiger RE, Stein PK, Bigger JT, Jr. Heart rate variability: measurement and clinical utility. Ann Noninvasive Electrocardiol.2005;10(1):88101 